\title{
Analisis Visual Wayang Kulit Eklektik "Ananta Yudha” Karya Is Yuniarto
}

\author{
Vania Anjani ${ }^{* *}$, Andrian Dektisa H. ${ }^{2}$, Asthararianty ${ }^{3}$ \\ 1,2,3 Program Studi Desain Komunikasi Visual, Fakultas Seni dan Desain, \\ Universitas Kristen Petra, Jalan Siwalankerto 121-131, Siwalankerto, Wonocolo, Surabaya. \\ *Penulis korespondensi; Email: vaniaanjani13@gmail.com
}

\begin{abstract}
Abstrak
Sejak Desember 2015, Is Yuniarto mengunggah karya visual figur wayang dengan visualisasi menggunakan percampuran figur wayang kulit nusantara dengan karakter-karakter figur superhero di akun media sosialnya. Salah satu karyanya yang terkenal adalah Wayang Ananta Yudha, yang muncul pada bulan April 2018. Karakteristik wayang Ananta Yudha merupakan representasi dari figur-figur pada film Avengers: Infinity War yang saat itu sedang ramai dibicarakan karena filmnya akan dirilis. Penelitian kualitatif ini bertujuan untuk memaknai bentuk visualisasi dan fenomena munculnya wayang Ananta Yudha, menggunakan metode deskriptif kualitatif dengan cara analisis memakai semiologi Barthes. Teori-teori yang dipakai adalah pop culture, eklektik, dan komodifikasi. Wayang Ananta Yudha menjadi ungkapan karya visual budaya populer yang merupakan pencampuran unsur-unsur masa lalu dengan masa kini, serta menjadi bentuk komodifikasi atas figur superhero karya Marvel Studio.
\end{abstract}

Kata kunci: Wayang Ananta Yudha, eklektik, Avengers: Infinity War, budaya pop, komodifikasi.

\section{Abstract}

Since December 2015, Is Yuniarto has been uploading his work of illustrated wayang pictures that used the combination of Indonesian wayang kulit with characters of superhero figures on his social media accounts. One of his famous works was Wayang Ananta Yudha, which he started posting in April 2018. Wayang Ananta Yudha was a representation of superhero figures from the movie Avengers: Infinity War, which was talked about a lot because the film was about to be released. This qualitative research is going to interpret the form of visualization and the phenomena of the appearance of Wayang Ananta Yudha, using descriptive qualitative method and analyzed with Barthes' semiology. This research uses pop culture, eclectic, and commodification theories. Wayang Ananta Yudha becomes a popular visual culture due to its combination of past and present elements which becomes a form of commodification on Marvel's Studio superhero figures.

Keywords: Wayang Ananta Yudha, eclectic, Avengers: Infinity War, pop culture, commodification.

\section{Pendahuluan}

Wayang, menurut Kamus Besar Bahasa Indonesia (KBBI) diartikan sebagai "boneka tiruan orang yang terbuat dari pahatan kulit atau kayu dan sebagainya yang dapat dimanfaatkan untuk memerankan tokoh dalam pertunjukan drama tradisional (Bali, Jawa, Sunda, dan sebagainya), biasanya dimainkan oleh seseorang yang disebut dalang". Dalam perkembangannya, wayang menjadi budaya dan seni yang sangat penting dalam sejarah Indonesia, yaitu sebagai salah satu metode penyebaran agama-agama di Indonesia, menyampaikan pesan mengenai perjuangan dan politik.
Seiring dengan berkembangnya zaman, wayang juga tidak lepas dari kemajuan teknologi. Beberapa tahun lalu, muncullah seni "wayang listrik" yang dikembangkan oleh seorang seniman asal Bali, I Made Sidia. Wayang listrik ini menggunakan proyektor dan lagu-lagu modern dalam penyajiannya.

Selain dalam bentuk wayang pertunjukan klasik, tradisional, dan mengikuti pakem, wayang juga dapat dirayakan dengan cara kontemporer. Hal ini dapat terlihat salah satunya dari gambar-gambar digital wayang kulit eklektik yang dibuat oleh Is Yuniarto, seorang ilustrator komik di Indonesia yang terkenal dengan komik ciptaannya berjudul 
Garudayana. Karya visual wayang kulit eklektik tersebut mulai muncul di sosial media pada akhir tahun 2015.

Visualisasi wayang tersebut menggunakan pendekatan pop culture, yakni menggunakan percampuran visualisasi wayang kulit Indonesia tradisional dengan kontemporer, sehingga menghasilkan karya wayang kulit khas yang memakai bentuk-bentuk yang berasal dari percampuran visual wayang masa lalu pada karakter figur masa kini (eklektik). Karya-karya wayang kulit digital itu diunggah di akun Instagram dan Facebook miliknya dan mendapatkan banyak apresiasi dari pengguna internet.

Eklektik berasal dari bahasa Yunani eklegein, yang artinya "memilih sesuatu". Sedangkan eklektisisme, menurut KBBI, adalah paham atau aliran filsafat yang mengambil yang terbaik dari semua sistem. Dalam dunia seni, eklektisitas memiliki kecenderungan untuk mengulang bentuk-bentuk lama, dan memadukan unsur-unsur dalam bentuk sendiri untuk dikembangkan menjadi bentuk yang baru.

Eklektisitas Wayang Ananta Yudha, diilhami dari komik dan film ternama Avengers: Infinity War buatan Marvel Comics. Ketika karya ini diunggah di media sosial, film Avengers: Infinity War sedang akan rilis dan sangat dinanti-nantikan oleh banyak orang diberbagai belahan dunia.

Visualisasi wayang Ananta Yudha ini menjadi fenomena yang menarik untuk dibahas, karena peneliti menduga visualisasi itu merupakan suatu kelanjutan euforia dari komik ciptaan Is Yuniarto sebelumnya (Komik Garudayana) yang memiliki banyak penggemar. Dengan begitu, Ananta Yudha menjadi bentuk baru dari "tradisi Is Yuniarto" yang mengambil tema kekinian.

Penelitian ini bertujuan untuk mengetahui bentuk visualisasi dan makna visual eklektik dari dari wayang kulit eklektik Ananta Yudha karya Is Yuniarto.

\section{Metode Penelitian}

\section{Metode Pengumpulan Data}

Pengumpulan data menggunakan teknik observasi mendalam, yaitu dengan mendokumentasikan gambar figur wayang Ananta
Yudha dari media sosial milik Is Yuniarto. Berdasarkan sumbernya, data dibedakan menjadi 2, yaitu data primer dan data sekunder. Data primer merupakan pemberi informasi utama, sedangkan data sekunder adalah data pendukung yang didapatkan atau dikumpulkan melalui pihak lain.

Data primer yang digunakan dalam penelitian ini adalah gambar figur-figur Ananta Yudha dan keterangannya yang didapatkan dari media sosial Is Yuniarto. Sedangkan data sekunder yang diperoleh berupa teori, data dan gambar-gambar pendukung yang didapatkan dari buku dan internet.

\section{Metode Analisis Data}

Penelitian ini menggunakan metode kualitatif. Analisis data kualitatif adalah upaya yang dilakukan dengan jalan bekerja dengan data, mengorganisasikan data, memilah-milahnya menjadi satuan yang dapat dikelola, mensintesiskannya, mencari dan menemukan pola, menemukan apa yang penting dan apa yang dipelajari dan memutuskan apa yang dapat diceritakan kepada orang lain (Bogdan; Biklen, 1982).

Metode analisis data yang digunakan pada penelitian ini adalah deskriptif kualitatif. Metode deskriptif adalah suatu metode yang berfungsi untuk mendeskripsikan atau memberi gambaran terhadap objek yang diteliti melalui data atau sampel yang telah terkumpul (Sugiyono, 2009). Analisis yang dilakukan secara deskriptif kualitatif ini akan dilakukan dengan memilah bentukan data, kemudian menemukan pola dari permasalahan yang ada. Setelah itu, analisis akan dilakukan untuk mengatasi rumusan masalah yang ada.

Untuk mempermudah pendeskripsian serta upaya pemaknaan atas gambar yang mendukung teori sebagaimana tersebut di atas, digunakanlah cara semiologi Barthes. Metode tersebut digunakan karena semiotika adalah ilmu yang berkaitan dengan relasi tanda dengan objeknya, relasi tanda dengan tanda lain, serta relasi tanda dengan interpretannya (Kurniawan, 2008).

Barthes menguraikan analisis tanda menjadi konotatif, denotatif, dan mitos. Tataran denotatif dalam penelitian ini adalah mengenai analisis figur wayang Ananta Yudha oleh Is Yuniarto secara visual. Tataran konotatif adalah menganalisis makna visual ini 
menggunakan perangkat teori-teori yang mendukung pemaknaan. Sedangkan level mitos untuk menegaskan pemaknaan atas objek material sebagai ungkapan operasionalisasi komodifikasi.

\section{Populasi dan Sampel}

Populasi adalah figur wayang-wayang eklektik karya Is Yuniarto. Kemudian dari banyak figur wayang eklektik tersebut dipilihlah sampel yang memiliki pengaruh paling besar pada pendukung pemaknaan. Maka dipilihlah figur wayang Ananta Yudha sebagai objek yang akan diteliti.

\section{Instrumen Penelitian}

Untuk mengumpulkan data, maka dibutuhkan instrumen PC (Personal Computer) untuk mengobservasi dan menyimpan gambargambar wayang Ananta Yudha dan untuk mencari referensi data dan teori-teori yang dibutuhkan di internet, dan buku referensi untuk teori-teori yang dibutuhkan dalam penelitian.

\section{Prosedur Penelitian}

Prosedur penelitian dimulai dengan mengidentifikasi problem yang akan menjadi objek material dalam penelitian, yaitu figur-figur wayang Ananta Yudha. Hasil identifikasi objek material tersebut kemudian menghasilkan beberapa pertanyaan yang kemudian diolah menjadi rumusan masalah. Untuk dapat melanjutkan penelitian, maka perlu mengumpulkan teori sebagai objek formal dan sekaligus memahami bagaimana teori-teori tersebut bekerja.

Objek material dan objek formal tersebut kemudian dikaitkan, dan dari hasil relasinya akan menjadi deskripsi pemaknaan. Dari deskripsi pemaknaan itu akan dibuat menjadi kesimpulan yang dapat menjawab rumusan masalah dan manfaat penelitian.

\section{Identifikasi Objek Formal dan Objek Material}

\section{Budaya visual}

Budaya visual mencakup pencitraan dalam segala jenis media, segala yang dapat dipersepsi secara visual. Menurut Sachari (2007), budaya visual melingkupi berbagai aspek yang berkaitan dengan wujud akhir sebuah gagasan manusia untuk 'mendunia', antara lain berwujud sebuah karya desain, atau berbentuk karya seni rupa (dalam arti luas), juga berbagai bentuk komunikasi visual, perumahan, media cetak, iklan, video klip, film, siaran televisi, mode pakaian hingga barang kebutuhan sehari-hari.

Bila ditelaah kembali, rentang waktu kehadiran visual jauh lebih lama ketimbang verbal. Namun, awalnya budaya verbal memiliki peranan yang dominan daripada budaya visual, karena pada masa itu budaya visual hanya diprakarsai oleh seni lukis saja, dan hanya bernaung di kalangan para patron dan gereja saja. Khususnya kecenderungan ini dimulai pada era Renaisans abad 12-13 Masehi. Hal tersebut membuat budaya visual terkesan hanya untuk kalangan elit saja (Pratiwi, 2017).

Namun sejak lahirnya alat fotografi dan disusul dengan perkembangan teknologi digital, hal-hal visual dapat dibuat dan disebarluaskan dengan sangat mudah. Hingga pada masa ini, minat membaca menurun (Saputri, 2017), karena banyak orang yang lebih suka melihat gambar atau sesuatu yang bersifat visual daripada hal-hal yang bersifat verbal/tulisan. Maka, industri film, animasi, periklanan, dan komik mengalami kemajuan yang sangat pesat.

Peran budaya visual yang melesat dan cenderung berubah-ubah ini membuat orang memiliki seleranya sendiri pada suatu topik tertentu. Topik yang sedang disukai banyak orang itu dapat disebut dengan "populer". Halhal populer juga seringkali dipakai orang untuk menjadi cara hidup mereka. Contohnya, ketika seseorang menyukai figur superhero tertentu, ia senang untuk berpakaian dan menggunakan benda-benda yang memiliki logo superhero kesukaannya itu.

\section{Pop Culture}

Pop culture, atau dalam Bahasa Indonesia disebut dengan budaya pop, sebenarnya adalah singkatan dari popular culture atau budaya populer. Williams memberikan empat makna yang mengandung pengertian "populer" yaitu:

1. Banyak disukai orang.

2. Jenis kerja rendahan.

3. Karya yang dilakukan untuk menyenangkan orang.

4. Budaya yang memang dibuat oleh orang untuk dirinya sendiri (Williams, 1983). 
Sedangkan kata culture, menurut kamus Cambridge diartikan "the way of life, especially the general customs and beliefs, of a particular group of people at a particular time". Dengan begitu dapat dimasukkan ke dalam pengertian pop culture berdasarkan arti katanya, di mana hal-hal "populer" yang banyak disukai orang menjadi sebuah budaya karena telah menjadi cara hidup mereka.

Payne (1998), seorang ahli ilmu sosial, mengatakan bahwa penggunaan istilah pop culture ini agak membingungkan, dan sering bertumpuk-tumpuk dalam tiga arti. Menurut Payne (1998), pop culture dapat didefinisikan sebagai: 1) Budaya yang diproduksi untuk orang-orang yang merupakan bagian penting dari pasar, sebuah komoditas yang membentuk konsumerisme, 2) Pop culture mengandaikan sebuah budaya yang berakar pada berbagai proses, relasi, dan nilai sosial tertentu, 3) Pop culture juga mengacu pada kualitas para konsumen dan audiens, berhubungan dengan perilaku mereka dan penggunaan barangbarang kultural sehingga dengan begitu untuk menjadi populer, film, fiksi atau musik harus dikonsumsi dengan cara-cara tertentu.

\section{Eklektik}

"Eklektik" berasal dari bahasa Yunani eklegein, yang artinya "memilih sesuatu". Sedangkan eklektisisme, menurut KBBI, adalah paham atau aliran filsafat yang mengambil yang terbaik dari semua sistem. Dalam dunia seni, eklektisisme memiliki kecenderungan untuk mengulang bentuk-bentuk lama, dan memadukan unsur-unsur dalam bentuk sendiri untuk dikembangkan menjadi bentuk yang baru. Sebuah contoh dari gaya eklektik berikut ini adalah karya visual yang dibuat oleh April Greiman untuk Institut Seni California, untuk merepresentasikan pendekatan multidisiplin dalam pekerjaannya.

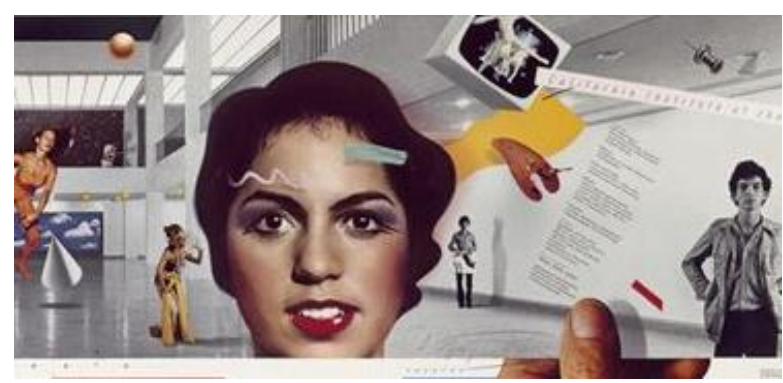

Gambar 1. Karya visual April Greiman, perhatikan figur penari tradisional di belakang (Sumber: agenciatelling.com, 2018)
Pada karya tersebut dapat ditemukan berbagai figur, misalnya adanya figur penari berbusana tradisional yang menggambarkan tradisi dan masa lampau, figur memakai busana dengan gaya fashion tahun 70-an, latar belakang sebuah gedung yang futuristik, dan wajah seorang wanita dengan gaya make-up modern.

\section{Komodifikasi}

Menurut kamus Cambridge, komodifikasi dapat diartikan sebagai keadaan di mana suatu hal diperlakukan sebagai komoditas (suatu produk yang dapat dibeli dan dijual). Dalam kata lain, komodifikasi adalah proses perubahan dari barang atau jasa menjadi komoditas. Seperti dikutip dari Mosco (2009), komodifikasi merupakan suatu proses yang menggambarkan bagaimana cara kapitalisme mendapatkan modal atau nilai melalui transformasi nilai sehingga memiliki nilai tukar atau komersial.

Dalam proses komodifikasi ini, sesuatu di produksi bukan semata-mata karena memiliki kegunaan bagi khalayak, tetapi lebih karena sesuatu itu bisa dipertukarkan di pasar. Menurut Mosco (2009), terdapat 3 dimensi komodifikasi media massa, yaitu:

1. Komodifikasi konten, merupakan proses perubahan pesan dari kumpulan informasi ke dalam sistem makna dalam wujud produk yang dipasarkan (Mosco, 2009).

2. Komodifikasi audiens, dimana audiens atau khalayak itu sendiri yang menjalankan fungsi komodifikasi, karena audiens-lah yang menentukan rating dari suatu media (Yakob, 2014). Menurut Fitra (2016), audiens merupakan komoditi penting untuk media media massa dalam mendapatkan iklan dan pemasukan. Media dapat menciptakan khalayaknya sendiri dengan membuat program semenarik mungkin dan kemudian khalayak yang tertarik tersebut dikirimkan kepada para pengiklan. Maka, semakin baik upaya pemahaman mengenai karakteristik dan keinginan audiens, semakin berhasil penjualan dilakukan.

3. Komodifikasi pekerja, yang berarti selain menjadi konsumen, secara tidak sadar audiens juga ikut memiliki andil dalam mentransferkan informasi kepada masyarakat lain melalui share status, gambar, dan video di berbagai jejaring sosial. Tindakan mereka itu membawa semakin banyak keuntungan bagi pemilik media. 


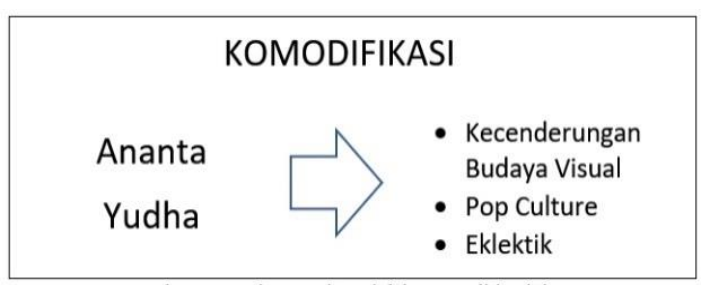

Gambar 2. Kaitan Antara Budaya Visual, Pop culture, Eklektik, dengan Komodifikasi (Sumber: Dokumentasi Penulis, 2018)

\section{Kajian yang Pernah Dilakukan Terhadap Objek Material}

Berdasarkan hasil penelusuran di kepustakaan Universitas Kristen Petra dan juga internet (Agustus 2018), belum ada penelitian ilmiah yang membahas tentang wayang eklektik Ananta Yudha karya Is Yuniarto. Namun, telah ada penelitian yang membahas mengenai wayang kontemporer di dalam judul "Perkembangan Wayang Alternatif di Bawah Hegemoni Wayang kulit Purwa" oleh Drs. Bedjo Rianto, M.Hum. dan Sayid Mataram, S.Sn., M.Sn. Penelitian ini membahas tentang bagaimana pegiat wayang kontemporer berjuang untuk menafsirkan, mengeksplorasi, dan mengembangkan kebudayaan wayang yang adiluhung mengikuti derasnya arus perkembangan jaman. Penelitian ini bersifat kualitatif deskriptif dan menggunakan metode sejarah.

Selain itu, ada pula penelitian dengan judul "Komodifikasi Kesenian Tradisional Wayang kulit Purwa" oleh Ismoyo Hartadi. Penelitian tersebut membahas tentang adanya komodifikasi kesenian wayang kulit purwa menjadi kesenian wayang dugem. Penelitian ini juga bersifat kualitatif dan menggunakan metode analisis deskriptif.

\section{Pembahasan}

\section{A. Bentuk Visual Wayang Ananta Yudha}

Seri Wayang Ananta Yudha terdiri dari 7 figur wayang (yang dikemas dalam 5 gambar) dan dapat dilihat di media sosial Is Yuniarto.

Gambar dari figur pada film Avengers: Infinity War dan figur-figur Wayang Ananta Yudha dilihat pada Gambar 3 hingga Gambar 8.

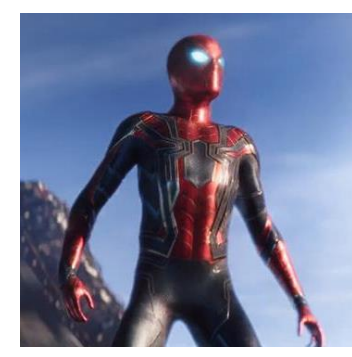

(a)

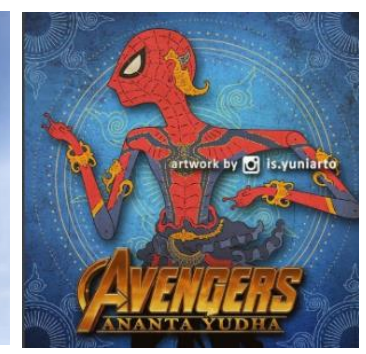

(b)
Gambar 3. (a) Karakter Spiderman dalam salah satu adegan di film Infinity War, dan (b) Figur Spiderman dalam Wayang Ananta Yudha

(Sumber: liputan6.com, movieweb.com, dan instagram.com/is.yuniarto, 2018)

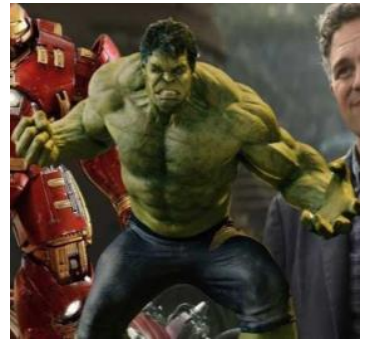

(a)

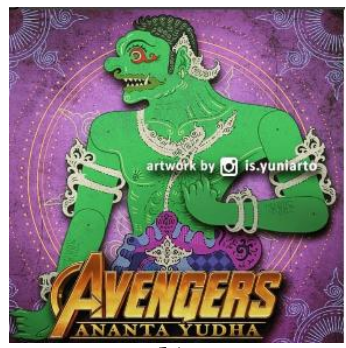

(b)
Gambar 4. (a) Figur Hulk dalam film Infinity War, dan (b) Figur Hulk dalam Wayang Ananta Yudha

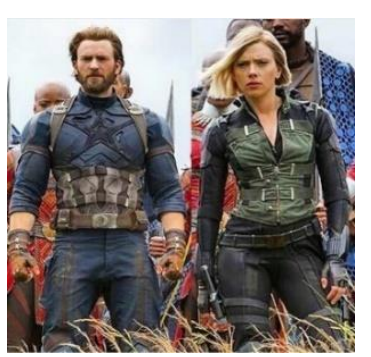

(a)

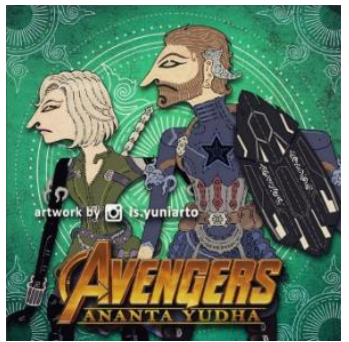

(b)
Gambar 5. (a) Figur Captain Nomad dan Black Widow dalam film Infinity War, dan (b) Figur Captain Nomad dan Black Widow dalam Wayang Ananta Yudha (Sumber: pinterest.com, dan instagram.com/is.yuniarto, 2018)

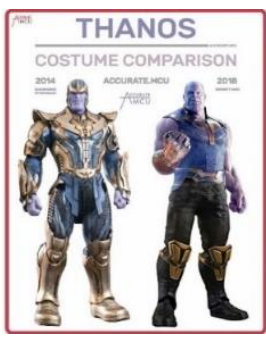

(a)

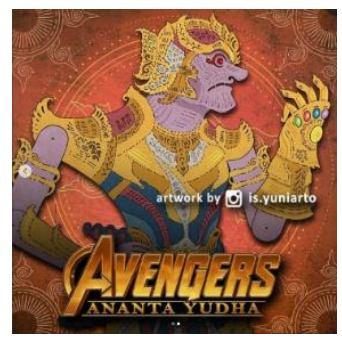

(b)
Gambar 6. (a) Figur Thanos dalam film Guardians of The Galaxy dan Infinity War, dan (b) Figur Thanos dalam Wayang Ananta Yudha (Sumber: pinterest.com, dan instagram.com/is.yuniarto, 2018) 


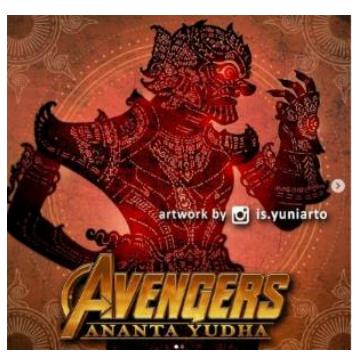

Gambar 7. Figur Thanos wayang Ananta Yudha dengan teknik visualisasi backlight seperti pada pementasan langsung wayang kulit (Sumber: instagram.com/is.yuniarto, 2018)

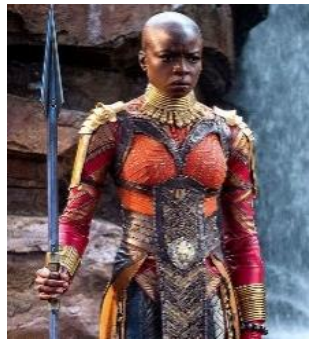

(a)

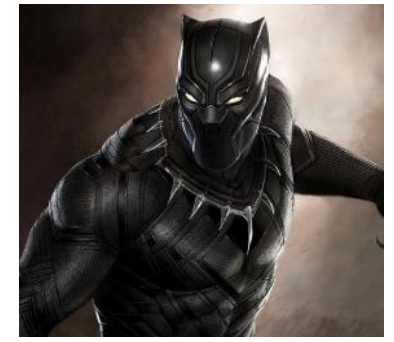

(b)

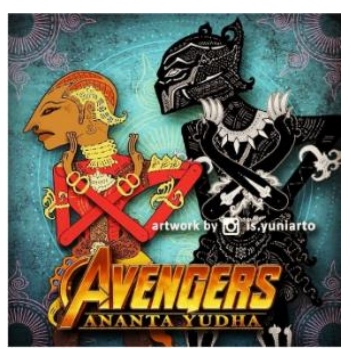

(c)

Gambar 8. (a) (b) Figur Dora Milaje dan Black Panther dalam film Infinity War (Sumber: wikia.com dan bioskoptoday.com, 2018), dan (c) Figur Dora Milaje dan Black Panther dalam Wayang Ananta Yudha (Sumber: instagram.com/is.yuniarto, 2018)

Oleh karena Wayang Ananta Yudha dibuat dengan mengikuti cara pandang Marvel Studios, maka visual figur-figur asli dari film Avengers: Infinity War di atas disertakan bukan dengan tujuan untuk membandingkan dengan figur-figur Wayang Ananta Yudha, melainkan untuk memudahkan dalam identifikasi figur asli pada masing-masing figur wayang.

\section{Simpingan}

Simpingan adalah susunan wayang-wayang yang tidak dimainkan oleh dalang pada saat pertunjukan. Wayang-wayang yang berjajar di sebelah kanan (menghadap kiri) biasanya adalah figur-figur yang berwatak baik, menjadi figur protagonis, seperti ksatria dan figur-figur dewa. Sedangkan yang diletakkan di sebelah kiri (menghadap kanan) adalah figur-figur seperti raksasa dan yang berwatak jahat (figur antagonis).

Wayang Ananta Yudha, yang hanya berupa gambar dan hanya digambarkan pada satu sisi saja, juga mengenal simpingan. Semua figur menghadap ke kiri kecuali figur Thanos (Gambar 10) yang merupakan figur antagonis di dalam film Avengers: Infinity War.

\section{Sumping Surengpati}

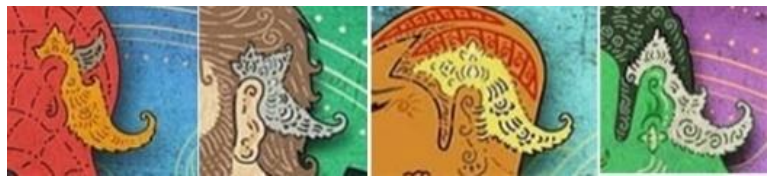

Gambar 9. Sumping yang divisualkan pada figur wayang Spiderman, Captain Nomad, Dora Milaje, dan Hulk (Sumber: Dokumentasi penulis, 2019)

Sumping adalah hiasan pada daun telinga. Arti kata sumping sendiri sebenarnya sebagai suatu kata kerja, yang berarti menyeimbangkan (Soetrisno, 2008). Aksesoris ini dipakai oleh hampir semua figur, kecuali figur Black Widow yang dapat dilihat pada Gambar 8, karena telinganya digambarkan tertutup oleh rambut. Menurut Pratama (2013), "Surengpati" sebenarnya memiliki makna, yaitu sura artinya berani, hing pati artinya kematian, yang berarti "tidak takut mati". Figur-figur tersebut memakai Sumping Surengpati untuk menekankan karakter "pahlawan" mereka seperti dalam semesta Marvel, yang digambarkan tidak takut mati dalam membela kebenaran dan berbuat kebaikan.

\section{Gelang}

Berikut adalah jenis-jenis gelang yang dipakai oleh 4 figur Wayang Ananta Yudha:
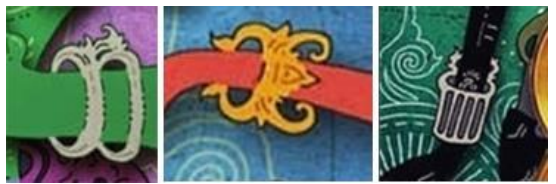

Gambar 10. Gelang Kana, Gelang Candrakirana, dan Gelang Black Widow (Sumber: dokumentasi penulis, 2019)

a. Gelang Kana, dipakai oleh figur Hulk dan Dora Milaje (Gambar 4b dan Gambar 8c). Menurut Widyokusumo (2010), dalam pewayangan tradisional, gelang ini biasanya dipakai oleh seorang ksatria atau seorang putri. Gelang ini dipakaikan pada figur Hulk serta Dora Milaje untuk menekankan 
sisi ksatria mereka, terutama pada Dora Milaje yang merupakan pasukan pertahanan khusus.

b. Gelang Candrakirana, dipakai oleh figur Spiderman (Gambar 3b). Dalam pewayangan tradisional, Gelang Candrakirana merupakan gelang yang hanya dipakai oleh Bima dan Hanoman. Seperti Spiderman, kedua figur pewayangan tersebut adalah figur yang juga berwatak baik, berani dan kuat.

c. Gelang Black Widow, dipakai figur Black Widow (Gambar 5b) bukan merupakan jenis gelang yang biasa ada di dalam pewayangan, namun lebih sebagai pelengkap figur wayang, sebagai representasi dari gelang yang dikenakan oleh figur asli Black Widow dalam film Avengers: Infinity War (lihat Gambar 5a).

\section{Kelatbahu}

Kelatbahu adalah aksesoris seperti gelang yang dipakai di lengan atas dekat bahu. Dalam pewayangan tradisional, kelatbahu berfungsi untuk menunjukkan kebesaran dan harkat martabat suatu figur wayang. Berikut adalah macam-macam kelatbatu yang dipakai oleh figur-figur Wayang Ananta Yudha:

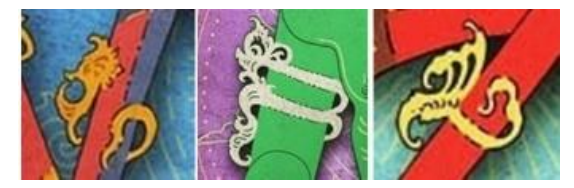

Gambar 11. Kelatbahu Nagamangsa, Denawa, dan modifikasi (Sumber: Dokumentasi penulis, 2019)

a. Kelatbahu Nagamangsa, dipakai oleh figur Black Widow, Captain Nomad, dan juga Spiderman.

b. Kelatbahu denawa dan kiwa, dipakai oleh figur Hulk dan Thanos.

c. Kelatbahu modifikasi, dikenakan oleh figur Dora Milaje dan Black Panther (lihat Gambar 8c) dan tidak memiliki referensi yang sesuai dengan yang dipakai pada pewayangan tradisional. Bentuk kelatbahu ini sudah dimodifikasi sedemikian rupa oleh sang ilustrator agar terlihat indah.

\section{Rapekan}

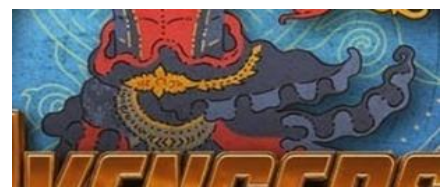

Gambar 12. Rapekan pada figur wayang Spiderman (Sumber: Dokumentasi penulis, 2019)
Rapekan adalah jenis "celana" atau busana bawahan yang dipakai pada wayang. Keseluruhan dari bentuk rapekan pada figurfigur Wayang Ananta Yudha tidak terlalu tampak karena tertutup oleh logo "Avengers: Ananta Yudha”.

\section{Bentuk Mata}

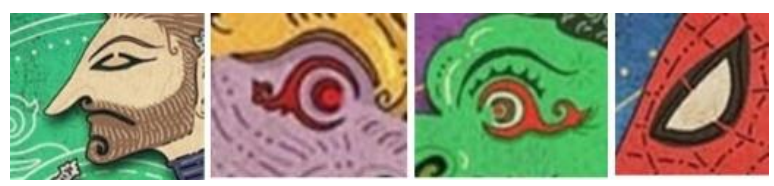

Gambar 13. Jenis mata nggabahan, telengan, plelengan, dan Spiderman (Sumber: dokumentasi penulis, 2019)

\section{a. Nggabahan}

Wayang tradisional dengan jenis mata ini biasanya tingkah lakunya halus, tajam, dan sungguh trampil dalam berperang (Soetrisno, 2008). Dalam Wayang Ananta Yudha, jenis mata ini divisualkan dalam figur Black Widow, Captain Nomad, Dora Milaje, dan Black Panther.

b. Telengan

Jenis mata ini dipakai oleh figur pewayangan Gatotkaca, mengesankan mata yang besar, awas, dan cara bergerak yang gesit/kasar. Visualisasi mata seperti itu digunakan pada figur Thanos (lihat Gambar 6b).

c. Plelengan

Bentuk mata ini mirip seperti bentuk telengan, namun terlihat lebih besar dan bundar. Jenis mata ini sebenarnya biasa dipakai oleh figur-figur jahat dalam wayang kulit tradisional, seperti figur Burisrawa. Namun pada Ananta Yudha, justru figur Hulk yang merupakan figur protagonis yang memiliki visualisasi jenis mata ini (lihat Gambar 4b).

d. Spiderman

Figur Spiderman dalam Wayang Ananta Yudha tidak memakai referensi bentuk mata seperti pada pewayangan tradisional, namun tetap mempertahankan bentuk mata dari figur Spiderman asli dalam film Avengers: Infinity War (lihat Gambar 3).

\section{Bentuk Hidung}

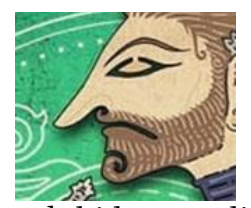

Gambar 14. Bentuk hidung wali miring pada figur wayang Captain Nomad (Sumber: Dokumentasi penulis (2019) 
Bentuk hidung 'wali miring' digunakan pada Wayang Ananta Yudha yang figur-figurnya manusia, seperti Black Widow, Captain Nomad, dan Dora Milaje. Bentuk hidung pada figur-figur wayang yang lain sudah merupakan modifikasi dan tidak ada referensi yang sesuai dengan bentuk pada wayang kulit.

\section{Pose}

Dalam Wayang Ananta Yudha, figur-figur tersebut digambarkan memiliki pose yang berbeda-beda, untuk menekankan sisi penokohannya dalam film Avengers: Infinity War. a. Spiderman, memiliki pose seperti figur Spiderman asli di Avengers: Infinity War, yaitu pose kedua tangan mengacungkan jari jempol, telunjuk, dan kelingkingnya (lihat Gambar 3b). Figur Spiderman di dalam film melakukan hal tersebut untuk mengeluarkan jaring laba-laba dari tubuhnya.

b. Hulk, (lihat Gambar 4b) tidak menunjukkan pose berkarakter Hulk sebagaimana tampilannya dalam film, namun hanya menekuk satu tangannya ke dada.

c. Black Widow dan Captain Nomad, Gambar 5b) tidak digambarkan dengan pose yang berarti.

d. Thanos (Gambar 6b) berpose dengan berkacak pinggang dan mengangkat satu tangannya (seperti akan menggenggam tangannya) menunjukkan obsesinya yang besar dalam mewujudkan apa yang diinginkan. Film Avengers: Infinity War menceritakan bahwa Thanos ingin mengurangi setengah dari populasi di seluruh semesta agar kehidupan dan alam kembali seimbang.

e. Dora Milaje dan Black Panther divisualkan dengan pose yang sangat menggambarkan karakter mereka di dalam film, yaitu pose untuk mengucapkan salam dari negara asal mereka, Wakanda (lihat Gambar 8b).

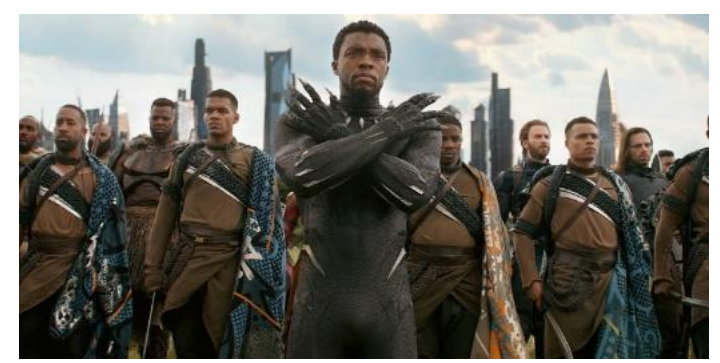

Gambar 15. Black Panther melakukan salam "Wakanda Forever" (Sumber: knowyourmeme.com)

Dalam film, salam tersebut berbunyi "Wakanda Forever" dan diiringi dengan gerakan menyilangkan tangan di depan dada, seperti yang digambarkan pada Gambar 8b. Wakanda Forever adalah gabungan dari Bahasa Kongo "kanda", yang berarti keluarga, dan Bahasa Inggris "forever", yang berarti selamanya. Salam tersebut menggabungkan dua bahasa berbeda, sehingga dapat dimaknai sebagai wujud hibrid dalam bahasa. Pose Wakanda Forever divisualkan pada Black Panther dan Dora Milaje untuk membuat figurfigur tersebut lebih mudah dikenali sebagai figur dari Avengers: Infinity War.

\section{Figur Wayang Ananta Yudha}

Selain elemen-elemen visual di atas, akan dijelaskan lebih lanjut mengenai masingmasing figur Wayang Ananta Yudha.

a. Spiderman

Figur Spiderman dalam film sangat dikenal dengan wujud kostumnya, yaitu warna biru dan merah, dengan corak garis-garis menyerupai bentuk sarang laba-laba. Selain itu topeng pada kostum Spiderman juga memiliki bentuk mata yang unik. Oleh karena itu, bentuk mata tetap dipertahankan dan tidak diganti dengan bentuk mata wayang tradisional agar figur wayang Spiderman tetap merepresentasikan figur Spiderman dalam film dengan baik.

b. Hulk

Figur wayang Hulk adalah figur satusatunya yang memakai kalung dari semua figur Ananta Yudha. Dalam pewayangan tradisional, kalung biasa dipakai oleh figur ksatria dan raja untuk menambah kesan wibawa. Figur ini juga figur satu-satunya yang telanjang dada, oleh karena itu untuk menambah "kesan wayang", maka ditambahkan kalung "ala wayang kulit" pada figur ini. Figur wayang Hulk juga digambarkan dengan bentuk mulut mrenges yang berdasarkan pada wayang kulit tradisional, bentuk yang biasanya dipakai oleh figur raksasa.

c. Black Widow

Karena figur wayang Black Widow digambarkan dengan rambut yang menutupi telinganya, maka Wayang Black Widow adalah figur satu-satunya yang tidak memakai aksesoris apapun di kepalanya, termasuk sumping. Figur ini digambarkan memakai kostum berwarna hijau olive dan hitam. Untuk memberikan "kesan wayang"nya, maka figur Black Widow ini digambarkan dengan mata, hidung, dan mulut seperti pada wayang kulit tradisional, dan memakai kelatbahu. Gelang yang dipakai oleh figur Black Widow dalam film Avengers: 
Infinity War juga ada pada figur wayangnya, dengan sedikit perubahan. Selain itu, di punggungnya, wayang Black Widow juga membawa senjata khasnya seperti di dalam film, yaitu baton atau tongkat yang dapat mengeluarkan aliran listrik yang sangat kuat.

d. Captain Nomad

Figur Captain Nomad dalam film, yang berambut pirang agak panjang dan disisir ke belakang, dan brewok yang lebat, digambarkan pula dalam figur wayangnya dengan amat serupa. Kostum yang di dalam film berwarna senada biru gelap (hampir hitam) dengan logo bintang di dadanya, divisualkan pada wayang Captain Nomad dengan warna biru yang lebih terang dan sedikit warna merah-putih di daerah perut. Memang figur ini dulunya bernama Captain America, yang terkenal dengan warna biru, merah, dan putih seperti pada warna bendera Amerika. Captain Amerika lebih dikenal karena sudah sering muncul di banyak film yang dibuat oleh Marvel Studios, sedangkan Captain Nomad adalah figur yang baru muncul, meskipun tetap diperankan oleh aktor yang sama. Film Avengers: Infinity War menampilkan figur Captain Nomad membawa tameng berwarna biru tua dengan teknologi canggih dari Wakanda. Pada figur wayang Captain Nomad, tameng ini juga ada namun digambarkan dengan motif ukir-ukiran di bagian tengahnya.

e. Thanos

Kostum yang dipakai oleh wayang Thanos pada Ananta Yudha ini bukan merupakan kostum yang dipakai figur Thanos dalam film Avengers: Infinity War. Sang ilustrator justru memakai referensi kostum figur Thanos yang muncul pada film Guardians of The Galaxy, yang rilis pada tahun 2014 (lihat gambar 10). Kostum figur Thanos dalam film Guardians of The Galaxy ini memang lebih menarik secara visual, karena terlihat mewah dan "ramai". Sedangkan figur Thanos dalam film Avengers: Infinity War hanya mengenakan semacam rompi berwarna biru, dengan sedikit aksen emas, dan tidak mengenakan apa-apa di kepalanya. Figur wayang Thanos memakai kostum dari film Guardians of The Galaxy, lengkap dengan helm-nya, dengan beberapa modifikasi seperti motif ukiran-ukiran dan bentuk lengkungan, dan ditambakan semacam sumping yang telah menyatu pada bentuk helm-nya. Bentuk dagu dari figur ini bukan merupakan bentuk yang biasanya ada dalam pewayangan tradisional, namun lebih menyerupai figur aslinya dalam film. Uniknya, hanya figur Thanos ini yang dibuatkan dua versi wayang, yaitu versi berwarna dan versi bayangan saja (lihat Gambar 7). Figur-figur lainnya hanya dibuat dengan versi berwarna saja.

f. Dora Milaje

Figur wayang Dora Milaje ini mengenakan kostum yang mirip dengan yang dikenakan oleh figur Dora Milaje pada film Avengers: Infinity War, namun tentu dengan sedikit modifikasi, penambahan motif-motif seperti batik. Namun tidak ada referensi batik tertentu yang digunakan, hanya berupa pola garis-garis sederhana.

g. Black Panther

Kostum yang dikenakan oleh figur wayang Black Panther dalam Ananta Yudha merupakan representasi dari kostum Black Panther yang dikenakan pada film Avengers: Infinity War. Namun alih-alih polos, kostum tersebut diberi motif seperti garis-garis batik. Sama seperti pada motif pada figur Dora Milaje, Figur Black Panther juga tidak menggunakan referensi batik tertentu, hanya berupa pola garis-garis sederhana. Wayang Black Panther digambarkan lengkap dengan cakar besi panjang dan semacam kalung dengan aksen cakar seperti yang ada pada film. Selain itu juga ditambahkan semacam sumping yang menyatu dengan penutup kepalanya, dan kelatbahu.

\section{B. Eklektisitas dalam Wayang Ananta Yudha}

Berikut adalah faktor-faktor pembentuk eklektisitas pada Wayang Ananta Yudha:

1. Zaman

Zaman dulu, wayang dipakai sebagai seni pertunjukan yang luhur. Orang yang memainkan wayang dalam suatu pertunjukan, atau disebut dalang, juga tidak bisa sembarangan. Bahkan untuk membawakan suatu kisah yang "keramat", dalang harus melakukan ritual-ritual tertentu.

Namun seiring berkembangnya zaman, wayang tradisional mulai "digantikan" oleh wayang kontemporer. Perubahan dari wayang tradisional ke wayang kontemporer ini sebenarnya bukan bertujuan untuk menghapus tradisi wayang Indonesia, namun justru merupakan suatu cara agar wayang tetap eksis di setiap masa, dan tidak 
"ketinggalan zaman". Sekarang semua orang bisa membuat wayang versinya sendiri dengan mudah, dengan meman-faatkan kemajuan teknologi.

\section{Teknologi visual}

Perbedaan teknologi visual juga merupakan suatu eklektisitas dalam Wayang Ananta Yudha. Dahulu, untuk memproduksi suatu bentuk visual hanya bisa dilakukan dengan metode manual yaitu digambar dengan tangan, diwarna dengan kuas, diukir, memakai cap, dan lain-lain. Namun kini, teknologi visual telah canggih dan memakai sistem digital, yang terkomputerisasi.

\section{Lakon/cerita}

Lakon, menurut KBBI adalah "peristiwa atau karangan yang disampaikan kembali dengan tindak tanduk melalui benda perantara hidup (manusia) atau suatu (boneka, wayang) sebagai pemain". Lakon jaman dulu biasa bercerita tentang kisah dewa-dewi, mengajarkan tentang kebaikan, bahkan tentang nilai-nilai ajaran Islam. Lakon pada film Avengers: Infinity War menceritakan soal teknologi super canggih dan manusia-manusia super yang bersifat ksatria dan berusaha menyelamatkan dunia dari figur jahat.

Dalam Wayang Ananta Yudha, terjadi percampuran antara lakon jaman dulu dan jaman sekarang, yaitu ketika figur-figur dalam cerita kepahlawanan dengan teknologi super canggih, digabungkan dengan figur dari cerita pewayangan tradisional.

4. Kepentingan

Zaman dahulu, karya seni seperti wayang dibuat menjadi pertunjukan dengan tujuan hiburan semata, terkadang untuk menyampaikan pesan-pesan dan menyebarkan ajaran agama tertentu.

Karya seni masa kini, dianggap sukses apabila dapat menimbulkan euforia dan dapat menjual. Contohnya. euforia atas suatu film yang akan rilis, dan banyak sekali orang membicarakan film tersebut, baik secara langsung maupun dalam media sosial, dan rela mengantri panjang untuk menonton film tersebut. Bahkan produkproduk lain yang tidak ada hubungannya, mulai dari hand-phone, sereal, mainan anak-anak, dan merchandise (baik resmi dari Marvel Studio atau buatan awam yang dijual di toko-toko online), menggunakan tema film tersebut untuk memasarkan produk mereka. Euforia tersebut menyebabkan film ini semakin laku keras, termasuk juga pemasukan dari lisensi yang dibeli oleh banyak pihak untuk menaruh logo, foto, atau gambar dari figur-figur film ini di produk mereka.

Euforia tersebut juga terjadi pada saat Avengers: Infinity War akan ditayangkan di negara-negara di seluruh dunia. Oleh karena itu, tidak mengherankan apabila film ini berhasil meraup keuntungan 2.047 miliar USD. Hampir dua kali lipat jika dibandingkan dengan film Avengers sebelumnya, Age of Ultron, yang memperoleh keuntungan 1.405 miliar USD.

Pada Wayang Ananta Yudha, kedua kepentingan tersebut bertemu ketika wayang eklektik ini ditujukan bukan hanya untuk menghibur, dan mengingatkan kembali akan tradisi Indonesia, namun juga sekaligus ikut merayakan euforia pop culture dengan segala konsekuensi komoditas maupun keuntungan yang dapat didapatkan.

Seperti yang dapat dilihat pada pembahasan di atas, eklektisitas pada wayang Ananta Yudha diambil dari hal-hal yang tidak terstruktur, karena seringkali dilakukan tanpa mengambil makna asli dari unsur-unsur yang digunakan. Unsur-unsur tersebut adalah wayang kulit tradisional, pop culture, dan hal-hal lain. Contohnya pada pengabaian figur antagonisprotagonis sebagaimana pakem pada wayang kulit, seperti yang terdapat pada visualisasi karakteristik bentuk mata Hulk dan Thanos. Contoh lain ketika kostum figur wayang Thanos bukan berdasarkan pada referensi film Avengers: Infinity War, namun berdasarkan film Marvel Studio lainnya, Guardians of The Galaxy. Dari dua contoh itu dapat dimaknai bahwa visualisasi figur Wayang Ananta Yudha hanya mengambil unsur visualnya saja tanpa mengambil makna konseptual tradisional yang melekat pada artefak.

Adanya "fenomena" pencampuran figur wayang dengan unsur pop culture sebenarnya bukanlah merupakan sesuatu yang baru. Hal tersebut sudah pernah dilakukan oleh $\mathrm{Ki}$ Catur, pembuat wayang hiphop, yang menggabungkan unsur hiphop dengan figur-figur pewayangan, pada visualisasi karakternya. 


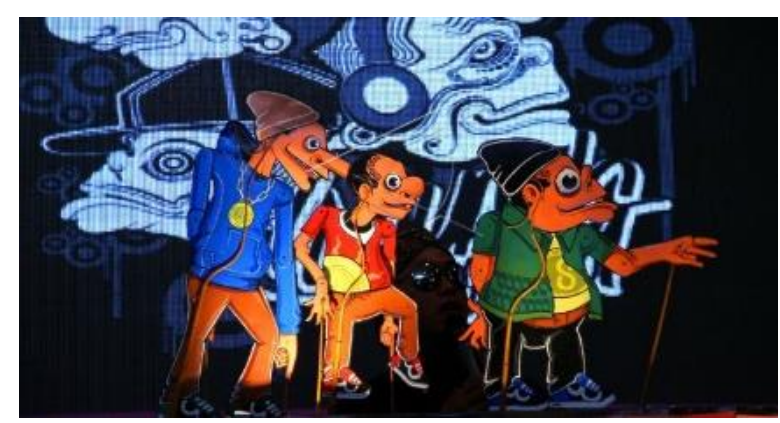

Gambar 16. Wayang hiphop (Sumber: antarafoto.com, 2018)

Selain wayang hiphop, ada pula Manzur Ghozaali yang membuat wayang eklektik dengan figur-figur pop culture. Karyanya tersebut sangat mirip dengan Wayang Ananta Yudha, namun dengan figur-figur yang berbeda. Bahkan karyanya sudah ada satu tahun sebelum kemunculan seri-seri wayang eklektik Is Yuniarto yang pertama (yang mengambil tema Star Wars). Dalam akun Behance-nya, Manzur memajang karyanya, seri Princess Mononoke dari Studio Ghibli, dalam rupa wayang kulit. Disusul pula oleh karya Manzur lainnya, seri figur Naruto dalam rupa wayang kulit.

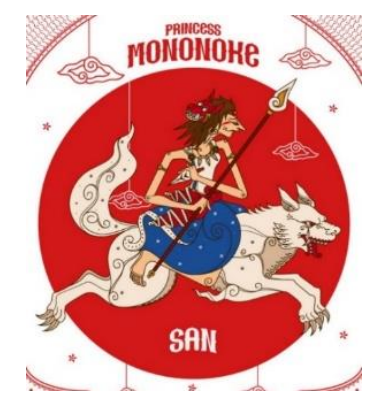

Gambar 17. Princess "Mononoke karya Manzur Ghozaali (Sumber: behance.net, 2018)

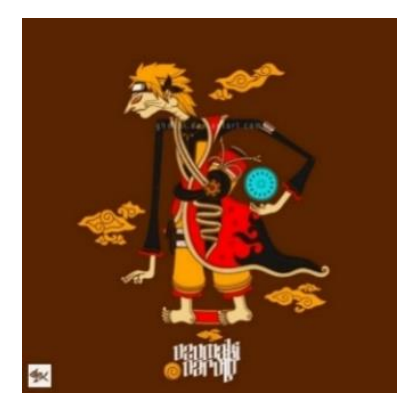

Gambar 18. Naruto karya Manzur Ghozaali (Sumber: behance.net, 2018)

Oleh karena itu dapat dimaknai bahwa eklektisitas Wayang Ananta Yudha sifatnya adalah sewenang-wenang, baik dari penataan dan percampuran referensi-referensi visual, dan bentuk-bentuk yang sebelumnya sudah pernah dilakukan oleh orang lain. Eklektisitas dalam Wayang Ananta Yudha dimaknai sebagai hal yang mengikuti kesenangan sang ilustrator.

\section{Eklektisitas Sebagai Komodifikasi Wayang Ananta Yudha}

Berdasarkan pada teori komodifikasi menurut Vincent Mosco (2009), maka komodifikasi dapat dibagi menjadi 3 tipe, yaitu komodifikasi konten, komodifikasi audiens, dan komodifikasi pekerja.

\section{Komodifikasi Konten}

Konten, dalam hal ini adalah yang menjadi objek material dari penelitian ini, yaitu Wayang Ananta Yudha. Pada pembahasan mengenai bentuk visual Wayang Ananta Yudha di atas, dapat diperoleh pemaknaan bahwa figur wayang tetap harus dapat merepresentasikan Avengers: Infinity War dengan baik, meskipun harus mengurangi unsur-unsur karakteristik visual wayang dari bentuk pakemnya.

Contohnya ketika figur Black Widow digambarkan dengan rambut terurai yang menutupi telinganya, sehingga tidak dapat memvisualkan sumping seperti figur-figur lainnya. Begitu juga pada figur Thanos, yang divisualkan dengan kostum mewah berwarna keemasan, penutup kepala, dan bentuk dagu yang unik (karena tidak berasal dari bentuk yang biasa ada pada wayang kulit). Namun dengan bentukbentuk visual seperti itu, kesan karakter visual wayang pada figur ini justru menjadi tak terlihat jelas.

Hal ini juga tampak pada karya Wayang Ananta Yudha yang menggunakan logo "Avengers: Ananta Yudha" yang cukup besar dan menutupi detail rapekan atau bagian bawah dari figur-figur tersebut. Logo ini memang penting, sebagai suatu identitas agar orang langsung mengidentifikasi adanya representasi film Avengers: Infinity War. Namun selain itu, hal ini bisa juga dimaknai sebagai usaha ilustrator Wayang Ananta Yudha yang sengaja menutupi sebagian gambarnya untuk menimbulkan kesan misterius dan membutuhkan penjelasan lanjutan agar menimbulkan rasa penasaran pada orang yang melihatnya. Dengan begitu, akan mendorong orang untuk mencari tahu lebih lanjut dan menanti-nantikan karya berikutnya. 
Seperti menurut Mosco (2019), untuk menarik lebih banyak konsumen, maka media seringkali mengisi kontennya dengan hal-hal yang lebih disukai oleh konsumen. Begitu pula pada Wayang Ananta Yudha, karena film Avengers: Infinity War saat itu sedang booming, dan banyak sekali orang membicarakan film tersebut, maka figurfigur Wayang Ananta Yudha dibuat sedemikian rupa sehingga orang akan langsung mengenali unsur film tersebut dalam gambar ini. Hal ini dapat dimaknai sebagai komodifikasi yang "meminjam" karakteristik Avengers: Infinity War sebagai pendongkrak popularitas Wayang Ananta Yudha. Dengan begitu akan semakin banyak orang yang mengapresiasi karya ini dengan like, komentar, atau mengikuti akun media sosial pembuatnya.

\section{Komodifikasi Audiens}

Selain menjadi konsumen, menurut Mosco (2009), audiens juga dapat menjadi sebuah komoditas, karena audiens-lah yang menentukan rating dari suatu media. Audiens dapat "dijual" kepada para pengiklan untuk mendapatkan keuntungan.

Penggunaan eklektisitas pada Wayang Ananta Yudha, selain dapat menghasilkan suatu bentuk baru dari percampuranpercampuran tersebut, tentu juga menghimpun kelompok baru sebagai pengamat. Respon akan suatu hal (baik positif ataupun negatif) yang dibagikan di jaman media sosial ini, tetap dapat menambah ketenaran hal tersebut.

Wayang Ananta Yudha sebagai suatu bentuk baru dari karya Is Yuniarto juga memiliki audiens-nya sendiri. Hal tersebut terbukti dari banyaknya jumlah likes dan komentar pada gambar-gambar Wayang Ananta Yudha di Instagram Is Yuniarto. Biasanya, posting lain (selain Ananta Yudha) rata-rata hanya mendapatkan seribu likes. Namun dalam seri Wayang Ananta Yudha ini, satu post mampu memperoleh hingga 3400 likes. Hingga kini, akun Instagram Is Yuniarto memiliki lebih dari 15.100 pengikut. Tidak hanya di Instagram saja, Is Yuniarto juga memiliki akun Facebook, yang diikuti oleh lebih dari 9200 akun lainnya.

Ketenaran pembuat Wayang Ananta Yudha yang bertambah oleh karyanya tersebut, dapat digunakan untuk mempromosikan dirinya sendiri untuk mendapatkan hal-hal lain, seperti diundang mengikuti event-event yang berhubungan dengan kartun atau manga. Bahkan karyanya tersebut dilirik oleh Walt Disney Company dan diajak bekerjasama untuk memberikan Wayang Ananta Yudha versi asli (wayang kulit) kepada para aktor dan sutradara dari film Avengers: Infinity War di Singapura.

\section{Audiens Sebagai Pekerja}

Dimensi lainnya dari komodifikasi menurut Mosco (2009) adalah audiens sebagai pekerja, di mana audiens selain menjadi konsumen dan komoditas, terkadang juga secara tidak sadar dapat menjadi "pekerja" yang memasarkan media yang dikonsumsinya. Contohnya ketika penggemar Wayang Ananta Yudha membagikan karya tersebut kepada orang lain yang belum mengetahuinya, baik melalui komunikasi langsung maupun menggunakan media sosial. Atau misalnya, jika pembuat Wayang Ananta Yudha mengadakan giveaway, dan mengharuskan orang-orang yang ingin mendapatkan merchandise secara gratis untuk membagikan karya tersebut di akunnya. Dengan begitu, mereka ikut "bekerja" untuk menambah ketenaran Wayang Ananta Yudha. Dengan semakin terkenalnya Wayang Ananta Yudha, tentu akan menambahkan semakin banyak keuntungan bagi pembuatnya.

\section{Muara Keuntungan dalam Komodifikasi Wayang Ananta Yudha}

Komodifikasi, sebagai suatu cara untuk memberikan nilai tukar akan suatu barang atau jasa, dilakukan agar pihak-pihak tertentu memperoleh keuntungan. Pada Wayang Ananta Yudha, unsur-unsur komodifikasi yang ditemukan dari penelitian ini tentu juga memberikan keuntungan bagi beberapa pihak, yaitu:

1. Keuntungan bagi Pembuat Wayang Ananta Yudha

Sejak Is Yuniarto menerbitkan komik Garudayana dan Grand Legend of Ramayana, yang kemudian terkenal sejak diterbitkan oleh Mizan dan dijual di Gramedia (dan toko-toko buku besar lainnya), namanya dikenal baik sebagai pencipta komik wayang setelah R.A. Kosasih. Selain komik, karya wayang eklektik yang dibuatnya juga mendapat perhatian yang cukup tinggi dari masyarakat Indonesia. Hal itu terjadi 
setelah karya wayang eklektiknya "dilirik" oleh pihak Walt Disney (perusahaan induk dari Marvel Studios), dan membuatnya berkesempatan untuk bertemu dan memberikan karya fisik dari wayang kulit eklektik, langsung kepada sutradara dan bintang filmnya pada acara launching film Avengers: Infinity War di Singapura.

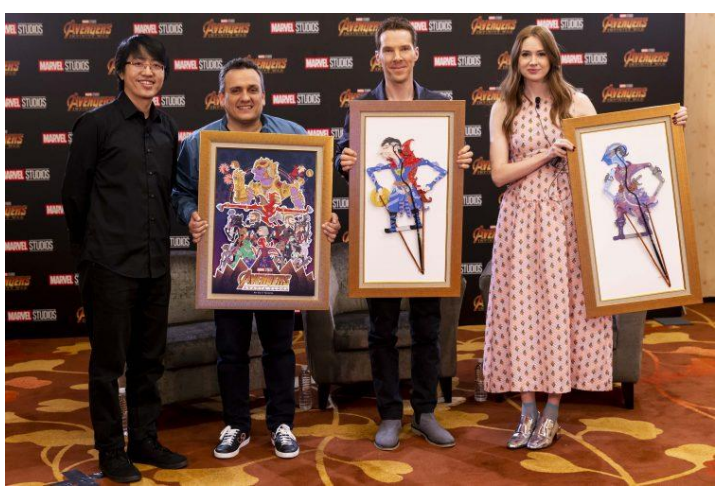

Gambar 19. Is Yuniarto bersama sutradara dan dua aktor film Avengers: Infinity War yang memegang karya wayang kulit eklektiknya (Sumber: cnnindonesia.com, 2018)

Sang ilustrator ini terus bekerja dalam bidang komik dan karya visual lainnya yang berhubungan dengan wayang, yang juga merupakan sumber pendapatan utamanya. Maka wajar jika karya Wayang Ananta Yudha dimunculkan olehnya di media sosial saat film Avengers: Infinity War akan dirilis. Pada saat itu, film tersebut mendapatkan perhatian yang amat besar, dan sangat dinanti-nantikan oleh banyak orang di seluruh dunia, termasuk di Indonesia. Selain ikut merayakan "euforia Infinity War", si pembuat karya juga memanfaatkan euforia ini untuk mendapat lebih banyak perhatian dan apresiasi dari publik, baik atas karyanya Wayang Ananta Yudha, maupun karya-karyanya yang lain. Dengan banyaknya orang yang "menemukan" Wayang Ananta Yudha di media sosial, kemudian menyukai, memberikan komentar, dan membagikannya ke orang lain, maka sang ilustrator akan mendapatkan peningkatan popularitas yang dapat digunakan untuk mempromosikan karyakaryanya yang lain, dan bahkan membuka peluang baru atas kesempatan untuk membuat karya lainnya yang menguntungkan.

\section{Keuntungan bagi Marvel Studios}

Seri film superhero Avengers oleh Marvel Studios, yang berisi gabungan dari figurfigur superhero ciptaan Marvel, memang sangat terkenal dan memiliki banyak penggemar dari berbagai belahan dunia dan segala kalangan usia (khususnya anak muda). Hal tersebut didukung oleh kehebatan dari pemasaran film ini, yang dilakukan dari pihak perusahaan itu sendiri dan hal-hal lain dari luar pihak Marvel yang ikut melakukan marketing atas film Avengers, yaitu perusahaan lain yang memproduksi barang maupun jasa, seperti contohnya makanan (sereal anak-anak, coklat, susu, dan lain-lain), peralatan makan, gadget, hingga perbankan. Selain itu, masih ada fanart dan fanpage yang saling membagikan informasi mengenai kabar terbaru dari film Avengers ke banyak orang melalui media sosial.

Wayang Ananta Yudha ini adalah salah satu contoh dari fanart film Avengers, yaitu seri Infinity War. Dengan membagikan karya tersebut di media sosial, pembuat Wayang Ananta Yudha bukan hanya menguntungkan dirinya sendiri, namun juga menguntungkan pihak Marvel Studios. Nama sang ilustrator yang sudah terkenal di Indonesia membuat media sosialnya memiliki banyak pengikut (terutama orang Indonesia). Para pengikut media sosialnya kemudian akan melihat Wayang Ananta Yudha dan mencari tahu lebih banyak mengenai film Avengers: Infinity War yang saat itu akan dirilis. Semakin banyak orang yang tahu dan menonton film ini, maka semakin besar pula keuntungan yang didapatkan oleh Marvel Studios.

\section{Simpulan}

Wayang Ananta Yudha dimaknai sebagai bentuk visual campuran unsur pop culture (Avengers: Infinity War) dengan karakteristik wayang tradisional nusantara. Wayang karya Is Yuniarto ini diunggah di media sosial miliknya pada saat film tersebut akan dirilis.

Visualisasi karakteristik Wayang Ananta Yudha dimaknai sebagai bentuk eklektik yang berasal dari faktor zaman, teknologi visual, lakon, dan kepentingan dari masa lalu dan masa kini. Namun sifat dari eklektisitas tersebut cenderung sewenang-wenang mengikuti kemauan sang ilustrator. Karakteristik Wayang Ananta Yudha hanya mengambil unsur visual dari artefak tertentu saja tanpa juga mengambil makna hakiki yang melekat pada artefak itu. Eklektisitas sebagaimana fenomena ini juga pernah dilakukan oleh orang 
lain dengan cara yang sama, yang sudah muncul di internet satu tahun sebelum Wayang Ananta Yudha populer.

Dari hasil penelitian, didapatkan pemaknaan mengenai unsur komodifikasi dalam eklektisitas Wayang Ananta Yudha (dalam penggolongan menurut teori Mosco (2009)) menjadi tiga dimensi dari komodifikasi. Pertama, komodifikasi konten, yaitu usaha yang dilakukan oleh pembuat Wayang Ananta Yudha, agar figur wayang tetap harus dapat merepresentasikan Avengers: Infinity War dengan baik, meskipun hal tersebut harus mengurangi unsur-unsur wayang tradisionalnya. Kedua, komodifikasi audiens, yaitu ketenaran pembuat Wayang Ananta Yudha yang bertambah oleh karyanya tersebut, dapat digunakan untuk mempromosikan dirinya sendiri untuk mendapatkan keuntungan-keuntungan lainnya. Yang ketiga yaitu audiens sebagai pekerja, di mana para penggemar dan pengikut (followers di media sosial) si pembuat Wayang Ananta Yudha ikut mempromosikan karya tersebut dan menambahkan popularitas dan "meninggikan" nama pembuat wayang.

Ketiga komodifikasi tersebut memiliki muara keuntungan, yaitu jalur keuntungan yang dihasilkan dari tindakan komodifikasi. Selain tentu bermuara ke si pembuat Wayang Ananta Yudha sendiri, keuntungan tersebut juga didapatkan oleh pihak Marvel Studios yang mendapatkan promosi gratis atas filmnya Avengers: Infinity War.

\section{Daftar Pustaka}

Agger, Ben. 2003, Teori Sosial Kritis: Kritik, Penerapan, dan Implikasinya, Kreasi Wacana, Yogyakarta.

Benedictus, Budi. 2018, Wayang Suluh, Wayang Perjuangan Kemerdekaan Indonesia, Retrieved June 4, 2018 from https://www.mobgenic.com/wayang-suluhwayang-perjuangan-kemerdekaanindonesia/.

Bogdan, Robert C., dan Biklen Kopp Sari, 1982, Qualitative Research for Education: An Introduction to Theory and Methods, Allyn and Bacon, Boston.

Cambridge Dictionary. 2018, Culture, Retrieved November 28, 2018 from https://dictionary.cambridge.org/dictionary/ english/culture.
Darmoko. 2009, Wayang Dan Negara: Wayang dalam Ideologi-Politik (2), Retrieved June 4, 2018 from

https://www.facebook.com/notes/wayang-

nusantara-indonesian-shadow-

puppets/wayang-dan-negara-wayang-

dalam-ideologi-politik-2/208372721109

Delaney, Tim. 2007, Pop Culture: An Overview, Retrieved September 10, 2018 from

https://philosophynow.org/issues/64/Pop_Cu lture_An_Overview

Dewan, Pauline. 2015, Words Versus Pictures: Leveraging the Research on Visual Communication, Partnership: The Canadian Journal of Library Information Practice and Research, 10(1), 1-10, Retrieved August 20, 2018 from

https://journal.lib.uoguelph.ca/index.php/pe rj/article/download/3137/3473/0

Endropoetro, Terry. 2016, Wayang Listrik dari Gianyar. Retrieved May 25, 2018, from https://www.facebook.com/notes/wayangnusantara-indonesian-shadowpuppets/wayang-dan-negara-wayangdalam-ideologi-politik-2/208372721109

Hazeau, G. A. J. 1987, Kawruh Asalipun Ringgit sarta Gegepokanipun Kaliyan Agami ing Jaman Kina Alih Aksara oleh Sudibyo, Balai Pustaka, Jakarta.

Kamus Besar Bahasa Indonesia. 2018, Eklektisisme, Retrieved November 28, 2018 from https://kbbi.web.id/eklektisisme

Kamus Besar Bahasa Indonesia. 2018, Wayang, Retrieved November 28, 2018 from https://kbbi.web.id/eklektisisme

Kurniawan. 2008, Semiotika Roland Bartes, Yayasan Indonesiatera, Magelang.

Mosco, Vincent. 2009, The Political Economy of Communication, SAGE Publications.

Mulyono, Sri. 1982, Wayang, Asal Usul, Filsasat, dan Masa Depannya, Gunung Agung, Jakarta.

Payne, Michael. 1998, A Dictionary of Cultural and Critical Theory, Blackwell Publishers, Britania Raya.

Pratama, Didi. 2013, Werkudara (2), Retrieved October 30, 2018 from

http://dhidipratama.blogspot.com/2013/03/w erkudara-2.html

Pratiwi, Julita. 2017, Apakah Sudah Terliterasi? Menelaah Budaya Visual Kini, Retrieved September 10, 2018 from http://jakarta32c.org/home/apakah-sudahterliterasi-menelaah-budaya-visual-kini/ 
Sachari, Agus. 2007, Budaya Visual Indonesia: Membaca Makna Perkembangan Gaya Visual Karya Desain di Indonesia Abad Ke20, Erlangga, Jakarta.

Saputri, Maya. 2017, Minat Baca Turun GaraGara Media Sosial, Retrieved August 20, 2018 from https://tirto.id/minat-baca-turungara-gara-media-sosial-cgDC

Soetrisno R. 2008, Wayang Sebagai Warisan Budaya Dunia, Penerbit SIC, Surabaya.

Sudarto. 1995, Metodologi Penelitian Filsafat, Raja Grafindo Persada, Jakarta.

Sugiyono. 2009, Metode Penelitian Kuantitatif, Kualitatif dan R\&D, Alfabeta, Bandung.
Susantio, Julianto. 2017, Wayang, Bukti Toleransi Hindu dan Islam, Retrieved April 18, 2018, from https://www.kompasiana.com/djuliantosusa ntio/wayang-bukti-toleransi-hindu-danislam_5895d0f5c5afbdb60abbd0b7

Widyokusumo, Lintang. 2010, Kekayaan Ragam Hias Dalam Wayang Kulit Purwa Gagrak Surakarta (Sebagai Inspirasi Desain Komunikasi Visual), Humaniora, 1(2), 402-414.

https://biz.kompas.com/read/2016/12/30/20155 5728/wayang.listrik.memadukan.wayang.d an.teknologi 